\title{
ESTUDIOS
}

\section{Realidad y Mitos Latinoamericanos en el Surrealismo Francés}

Es una actitud común en los surrealistas franceses tanto como en otros grupos de vanguardia, entre los que se cuentan los expresionistas alemanes, la asimilación del impacto de las ideas de Freud y C. G. Jung acerca de la importancia del mito y de la magia, fenómenos que habían sido un tanto extraños o fuera de la comprensión de la mentalidad racionalista de siglos anteriores. Hay que recordar la conversación de Jung con un cacique del pueblo Tao, en Nuevo México, ${ }^{1}$ en la que el profesor vienés obtiene la revelación del sentido de la creencia mágica y de la fuerza del mito en un hombre indio americano, en cuyo diálogo descubre que no piensa con la cabeza sino con el corazón y descubre también el sentido de su religión misteriosa y no racional.

El surrealismo "cree obtener del caos del subconciente, del sueño y de las manifestaciones intactas y espontáneas del alma, un nuevo conocimiento, una nueva verdad, un arte que diga más a los hombres".2

Por eso los surrealistas volvieron los ojos a México y otros países de Amética Latina, en cuyos pueblos hallaron confirmación o asidero para sus teorías estéticas o una concepción más profunda del arte o de la vida.

${ }_{1}$ C. G. Jung, Erinnenungen, Träume, Gedanken, Zürich, Rascher Verlag, 1962, y en trad. castellana: Recuerdos, sueños y pensamientos, Barcelona, Seix Barral, 1966 , p. 254 .

2 Arnold Hauser, Literaturca y manierismo, Madrid, Ediciones Guadarrama, 1969, p. 219. 
De otro lado, los estudios de James Frazer en La rama dorada, ${ }^{3}$ y sus discípulos de la nueva antropología, han dignificado, en el presente siglo, el pensamiento y la concepción del mundo del hombre primitivo. Extrayendo su estudio del terreno de las instituciones bárbaras o pertenecientes al reino de la superstición o de la brujería, se ha abierto un nuevo campo de exploración para los creadores en general y en especial para los europeos hastiados de los contenidos tradicionales ya exhaustos que, a su vez, engrilletaban las gastadas formas.

En paralelismo muy coincidente con los expresionistas alemanes, bullentes en el mismo estado de espíritu, los creadores de varias generaciones surrealistas, en afirmación plural, descubrieron en América sugestivas fuentes para sus motivos de inspiración renovadora.

En el culto vudú y lo ritos haitianos, en las impresiones de la Martinica, en el estudio de los mitos o en la leyenda de la floresta amazónica, se encontró una fuente viva, de la que brotaba la fascinación del misterio, de la fantasía, de lo maravilloso exhuberante y de los cultos mágicos.

El plano era coincidente también en la admiración por ciertos creadores del pasado como Baudelaire, Poe y Lautréamont que habían bebido en los insondables arcanos de lo desconocido y la irracionalidad del mito y de la magia, de las rarezas profundas y misteriosas. Isidoro Ducasse (Conde de Lautréamont, 1846-1870) poeta nacido en Uruguay aunque de habla francesa, habria dado el impulso anticipado para la renovación de la poesía lírica europea, o sea el primer germen del surrealismo con su único y genial libro Los cantos de Maldoror."

De otro lado, Roger Caillois, actuante y crítico del surrealismo, ha recordado el pasrno ingenuo de André Breton ante el prodigio de los guisantes saltarines que alguien había llevado de México a París en 1925. Por su parte, André Breton vivió unos meses de 1937 en México y por la misma época Antonin Artaud iniciaba su peregrinación por tierras aztecas, seguido más tarde por Benjamín Péret.

Llegó así a producirse, como afirma Alan Bosquet,

una ósmosis entre el surrealismo y los hábitos de pensar autóctonos (latinoamericanos)... una tradición antigua vuelve a encontrar allí un prejuicio moderno y un impulso natural se afirma sobre una determinación tenaz... pues la época de los años 50 es pro-

3 James Frazer, La rama dorada, México, F. de C. E., 1959.

4 Comte de Lautréaumont, Les chants de Maldoror, Paris et Bruxelles, 1874. 
picia a tales síntesis... El mundo cartesiano agota sus últimos recursos de imaginación...

De tal suerte, la experiencia surrealista, que estaba a riesgo de caer en lo artificial y lo forzado, ha de encontrar nuevas fuentes en las manifestaciones de la sensibilidad precolombina.

Latinoamérica - $-\mathrm{y}$ todo mundo extraño o poco conocido- adquiere singular prestigio ante los surrealistas animosos de confirmar sus tesis. Muchos de ellos encontraron elementos sugestivos en estas tierras, sin. gularmente en México, en las Antillas (Haití, Martinica, Cuba) y en América del Sur. Los guiaba esa "búsqueda de Jo maravilloso en tanto que realidad", según el enunciado de Georges Lafourcade, ${ }^{6}$ que se complementa con la propia formulación teórica de André Breton en su Primer Manifiesto (1924): "En el dominio de la literatura, sólo lo maravilloso es capaz de fecundar la obra". De tal suerte, la aproximación de los surrealistas a América Latina no es obra del azar o del capricho. Respondía a la necesidad de hallar nuevos ingredientes y preciosos contenidos en la magia y el mito de estas regiones. Los impulsaba una angustia y el deseo de lograr una meta que consistía en descubrir la realidad del yo profundo, del inconsciente oculto en la profundidad de las almas y de los siglos.

El surrealismo quiso superar el límite del sueño a que lo constreñía su aliento individualista — vigoroso sin duda en Breton-y buscó campo más amplio y más acorde con una concepción colectivista, en el territorio del mito. En pos de él, buscó ámbito tico e inexplorado en las antiguas culturas de América, México, Guatemala y Perú: las mesetas mexicanas, el trópico centroamericano o antillano, los Andes sudamericanos y las llanuras amazónicas. Allí estaban intocados parajes inverosímiles y habitantes impolutos que vivían sus concepciones míticas originales creadas por las grandes culturas de América, en nada semcjantes a la mitología convencional de griegos y germanos. $\mathrm{Y}$ en estas comarcas se proyectaron Artaud, Rousell, Péret, Michaux, al igual que expresionistas alemanes como Döblin y Edschmid, el neorromántico Eduard Stucken y el objetivista Arnold Höllriegel.

Para un francés de mentalidad típicamente francesa, dice Hatzfeld, el dejar atrás las fronteras de Francia ha significado siempre huir hacia una superrealidad no-francesa, aventura romántica y

5 Alan Bosquet, Verbe et Vertige, Paris, Hachette, s.f., p. 188.

6 "Notes sur le roman français contemporaine", en The University of Buffalo Studies, VI, abril, 1939, N? 2, p. 88. 
exótica. Y desde la evasión de Rimbaud, ha sido algo más aún: un rodeo para llegar a los reinos del espiritu, una obsesión que induce al "enfant prodigue" de Gide, después de naufragar en su "vuelta", a prestar ayuda a su hermano mayor para que también escape. En el siglo veinte, el objeto del escapismo exótico es una fantástica fuga a desconocidos "países de maravillas" como América... ${ }^{\top}$

Tal era, sin duda, el caso de Paul Morand o Valéry Larbaud, o del paisajismo sentimental de Pierre Loti, quienes para llenar un vacío sin posibilidad de colmarse, para encontrar "lo extraño" del sueño o pata recrearse en la "fantasía irónica", se volcaron también hacia otras tierras lejanas. Se trataba de encontrar una superrealidad transformadora o transfiguradora.

Pero Ia actitud de los surrealistas constituye, como hemos de ver, algo más que un aparente "evasionismo exotista", según quiso enunciarlo Hatzfeld.

La experiencia mexicana de André Breton fue positiva y también política, pues de ella nació un manifiesto que firmó con León Trotsky y Diego Rivera en 1938: "Por un arte revolucionario independiente".

La "evasión" es aparente y el "exotismo" no existe. Hacia América se enrumban Breton y sus compañeros literarios para superar el nihilismo que penetraba su negación de la cultura y el arte tradicionales. Más que evasión fue una actitud de búsqueda y de regeneración, ya que se daban cuenta del negativismo y la artificiosidad que los invadía. No los atraía, de otro lado, lo exótico americano, sino el descubrimiento de nuevos elementos para la creación latentes en el Nuevo Mundo coincidentes con los presupuestos surrealistas. Fueron conscientes de que se dirigía en peregrinación a las fuentes del mito y la magia latinoamericanas.

Quizás obscuramente - dice Juan Larrea- Breton percibe que, siquiera en simbolo, ha traspuesto el Mar Tenebroso que bañaba el fin de la tierra de donde procede y ha puesto pie en el auténtico mundo de la Realidad, allí donde el surrealismo ha de ceder el paso a un nuevo y más positivo movimiento. ${ }^{8}$

7 H. Hatzfeld, Superredismo, Buenos Aires, Ed. Argos, 1946, pp. 71-78.

8 J. Larrea, Del surredismo a Macbu piccbu, México, Joaquín Mortiz, 1967, p. 39. 
$Y$ asi se expandió por Estados Unidos, las Antillas y México. $Y$ no sólo a esas regiones, pues también llegaron integrantes del grupo a la América del Sur, según veremos.

$\mathrm{Y}$ agrega Larrea:

el surrealismo último producto poético del mundo occidental, en su tendencia a su superación futura, indica y revela que el reino de la Realidad se ubica en el Nuevo Mundo y se relaciona con el contenido de los sucesos españoles y con su "mito inmenso" (p. 66)... " $\mathrm{L}$ a trascendencia surrealista... apunta de un modo decisivo hacia el Nuevo Mundo..." (p. 73).

El interés e inquietud de los surrealistas por los elementos mágicos y humanos de lo latinoamericano se puede advertir años después en varias páginas del Almanach surréaliste du demi-siècle, publicado por Breton y Péret. ${ }^{9}$

Aparte de un relato poético del mexicano Octavio Paz sobre el culto y significación de la "mariposa de obsidiana" de los antiguos aztecas, figura allí el ensayo polémico de Benjamín Péret titulado " $\mathrm{La}$ soupe déshydratée", en cuya parte inicial rectifica el error de confundir lo maya y lo azteca, separados más de diez siglos en el tiempo y millares de kilómetros en el espacio, y de considerar que las formas precolombinas son abstractas por el hecho de que "no imitan las formas del mundo exterior". Ello significaría confundir dos procesos: lo que es abstracción con lo que es decantación operada con la contribución de múltiples culturas.

Todo lo cual le sirve para una ágil disertación acerca de la naturaleza y proyección del arte abstracto.

En otros trabajos del mismo Almanaty hay referencias acerca del arte de la América precolombina (como en el de André P. de Mandiargues) o la mención de Restif de la Bretonne (1734-1806), célebre erotólogo o erotógrafo y utopista francés, quien voló imaginariamente de Francia a la Patagonia, y de quien se ocupa un precursor del surrealismo como Maurice Heine (1884-1940).

Más adelante, Antonin Artaud publica su ensayo "La conquista de México" como elemento para el "teatro de la crueldad" y para la actualización de los problemas de una supuesta superioridad occidental, de la oposición entre el cristianismo y una falsa idea del paganismo $y$ de otro lado, el esplendor, la poesía y el fondo metafísico de las reli.

${ }^{2}$ En la NEF, Paris, Editions du Sagittaire, Nos. 63-65, marzo-abril de 1950. 
giones naturales americanas. Traza así las posibilidades de esa conquista y sus elementos mágicos como tema dramático en cuatro actos: 1) los signos "avant-coureurs", 2) la confesión, 3) las convulsiones y 4) la abdicación.

El mundo haitiano tiene para Gilbert Lely connotaciones sugestivas. $Y$ finalmente B. Péret traduce un fragmento del Libro de Cbilam Balam de Chumayel, en Yucatán, expresión de contenido mítico de los antiguos mayas, tal como lo hacen para el sector antillano André Mas$\operatorname{son}^{10}$ y Michel Cournot.

Por su parte, Henri Michaux hizo el recorrido sudamericano entre diciembre de 1927 y enero de 1929, desde Quito a los volcanes andinos y de allí a la selva amazónica. Excursionó por Ambato y Riobamba hasta el Pastaza y regresó luego a Quito para visitar a Otavalo y seguir finalmente la ruta de la selva amazónica. Va anotando observaciones en prosa y poemas, que organiza más tarde en un libro vario y algo inorgánico que titula Ecuador. ${ }^{11}$

Los Andes ecuatorianos causan hondo impacto en su sensibilidad. En un poema parece resumir su captación de la esencia paisaje-hombre:

\section{LA CORDILlERA DE LOS ANDES}

La primera impresión es terrible y próxima a la desesperanza.

El horizonte de acceso desaparece.

Todas las nubes no son más altas que nosotros.

Infinitamente y sin accidentes ellas están

en donde nosotros estamos,

las altas mesetas de los Andes que se extienden, que se extienden.

No seremos de tal modo ansiosos.

Es el mal de la montaña que nos invade,

el asunta de estos días.

El suelo es negro y sin acogida.

Un suelo venido de lo interior.

No se interesa en las plantas.

Es una tierra volcánica.

¡Desnudo! y las casas negras encima,

10 A. Masson, Martinique charmeuse de serpents, Paris, Hachette, 1956.

11 H. Michaux, Ecuador, Journal de voyage, Paris, NRF. Gallimard, 1929. 
Lo dejan en toda su desnudez;

El desnudo negro del mal.

Quien no ama las nubes,

Que no venga al Ecuador.

Ellas son los perros fieles de la montaña,

Grandes perros fieles;

Coronan en lo alto el horizonte;

La altitud del paraje es de 3000 metros,

según dicen,

es peligroso según dicen, para el corazón,

para la respiración, para el estómago

y para el cuerpo todo entero del extranjero.

Rechonchos, braquicéfalos, a paso corto, pesadamente cargados, marchan los indios

en este pueblo, pegados en un cráter de nubes.

¿Dónde va este peregrinaje encorvado?

Se cruza y se entrecruza y asciende: nada más:

es la vida cotidiana.

Quito y sus montañas.

Ellas caen sobre él, después se asombran, se moderan, ¡calman sus lenguas! es el

camino; después de esto se las empiedra.

Fumamos todos aquí el opio de la gran altitud en voz baja, a paso corto, a pequeño aliento.

Poco se disputan los perros, poco los niños, que poco tíen.

(De Ecuador, París, 1929, obra citada, trad. de Estuardo Núñez).

No siempre es la imersión en las profundidades anímicas, pues en su diario en prosa deja algunas notas de aguda captación: "El poncho de color brillante y oscuro es una alegría constante para mí. Es el triunfo espléndido sobre la tierra negra", o esta otra frase: "Sólo saben reír los indios que no han conocido la opresión del blanco".

Pero acaso su deslumbramiento mayor ocurre ante la selva sudamericana, que recorre en piragua por el Pastaza y el Napo hasta la fron- 
tera del Perú (Aguarico), para ingresar luego al Amazonas. Después de una breve visita a Iquitos y otra a Manaos, sigue el descenso por el Amazonas hasta el Atlántico.

Y su conclusión parece ser una frase sugerida por ese portentoso esplendor de la naturaleza americana que le tocó vivir con intensidad y fervorosa admiración de europeo deslumbrado:

Dentro de algunos cientos de años, confío, el mundo será grande. En fin, se comunicará con los animales, se les hablará. Cortos de espíritu serán los que no se den cuenta de este movimiento general y de la significación de multitud de puntos científicos y parasíquicos en esta dirección (p. 79).

Antonin Artaud (1896-1949), es el poeta $y$ autor de teatro en quien sobrevive todavía, hasta entrada la cuarta centuria del siglo, la actitud surrealista. Para él, la experiencia latinoamericana parece capital. En 1936 vive y escribe en México sus Textos mexicanos para un nuevo mito, además de otro libro trascendente, En el país de los taribumaras.

En México halló "el viejo totemismo de los animales y de las piedras", las fuerzas de la cultura que no están en los libros, la vuelta a la naturaleza y el reencuentro de la vida. Afirmó allí su concepto de que "lo que ha hecho perder la cultura es nuestra idea occidental del atte", ${ }^{12}$ la cual ha olvidado las fuerzas espontáneas que nacen de los mitos y formas totémicas.

La verdadera cultura actúa por su exaltación y por su fuerza, y el ideal europeo del arte pretende que el espíritu adopte una actitud separada de la fuerza, pero que asista a su exaltación. Idea perezosa, inútil, y que engendra la muerte a breve plazo. Las múltiples vueltas de la Serpiente de Quetzalcoatl son armoniosas porque expresan el equilibrio y las fluctuaciones de una fuerza dormida; y la intensidad de las formas sólo se da allí para seducir y captaí una fuerza que provoca, en música, un acorde desgarrador... A nuestra idea inerte y desinteresada (y petrificada) del arte, una cultura auténtica opone su concepción mágica y violentamente egoista, es decir, interesada. Pues los mexicanos captan el Manas, las fuerzas que duermen en todas las formas, que no se liberan si con-

12 A. Artaud, El teatro y sa doblo, Buenos Aires, Ed. Sudamericana, 1964, pp. $10-12$. 
templamos las formas como tales, pero que nacen a la vida si nos identificamos mágicamente con esas formas. Y allí están los viejos tótems para apresurar la comunicación. ${ }^{13}$

$Y$ estas ideas deriva su nueva concepción del teatro que debe valerse de todos los lenguajes, o sea, los gestos, sonidos, palabras, fuego, gritos. Porque todo conduce a rechazar "las limitaciones habituales del hombre $\mathrm{y}$ de los poderes del hombre, $y$ a extender infinitamente las fronteras de la llamada realidad".

A raíz de su regreso de México, en noviembre de 1936, Artaud escribió el libro Viaje a México, del cual era una parte importante el "Viaje al país de los Tarahumaras". Aquel libro apareció finalmente, después de algunas vicisitudes que Artaud relata en una carta a su amigo André Parisot, con el título Les Tarabumaras ${ }^{14}$ y se complementó con otros trabajos concernientes al mismo tema que subsanaron páginas perdidas del libro primitivo.

Artaud residió en México, en el curso de 1936, después de breve estada en Cuba, y realizó el propósito de conocer al país en profundidad, estudiar a sus indios e iniciarse en sus prácticas mágicas. Y sobre todo, pudo hacer realidad, una vez estudiados esos secretos, el "verdadero" drama (según afirma en carta a Barrault). Pudo encontrar allí, al norte de México, "la raza de los hombres perdidos", como él llamó a los tarahumaras, una "raza príncipe", que vive en estado antediluviano $y$ en un mundo terriblemente anacrónico.

Esta tribu "resiste hace más de cuatro siglos todo lo que la ha atacado: la civilización, el mestizaje, la guerra, el invierno, las bestias, las tempestades y la floresta... Por más increíble que parezca, los indios tarahumaras viven como si estuvieran ya muertos. Ellos no caminan sobre la realidad y sacan las fuerzas mágícas del menosprecio que sienten por la civilización". (p. 137)

Movía a Artaud el desaliento frente a la civilización y la desesperanza en las formas culturales europeas. Son suficientemente expresivas las citas siguientes:

La cabeza de un europeo de hoy es una cueva o almacén de sí-

13 A. Artaud, Les tatabumaras, Décines (Isére), L'Arbaléte-Marc Barbezat, 1955. p. 212.

14 A. Artaud, Les tarabumatas, cit.; en esta edición se inserta lia carta a Párisot. 
mulacros sin fuerza que Europa toma por sus pensamientos (p. 189) ...

...sólo abusivamente y de manera sólo verbal, se puede todavía osar hablar, en Europa, de civilización (p. 162)

Toda verdadera cultura se apoya sobre la raza y sobre la sangre. La sangre india de México guarda un antiguo secreto de raza y antes que la raza se pierda, pienso que debemos pedir la fuerza de ese antiguo secreto. En vez de que México actual copie a Europa, es para mí la civilización de Europa la que debe pedir a México un secreto. La cultura racionalista europea está ea quiebra y yo he venido a la tierra de México a buscar las bases de una cultura mágica que puede todavía resplandecer con las fuerzas del sol indio (p. 182).

Enunciaba, de tal suerte, un ideal desalienante que mueve a los espiritus latinoamericanos. Se volcaba hacia las formas ocultas e intactas que pudo hallar en América Latina, y decía:

nuestro mundo ha perdido su magia. Si la magia es una comunicación constante del interior al exterior, del acto al pensamiento, de la cosa a la palabra, de la materia al espíritu, se puede decir que después de largo tiempo hemos perdido esta forma de inspiración nerviosa, y que necesitamos volver a fortalecernos en estas fuentes todavía vivas y no alteradas. Está bien que se distribuyan las tierras y que las riquezas puedan todavía circular pero se dice que en México, y al mismo tiempo que los indígenas recobren las tierras de las que la raza fue desposeída, una escueia activa busca sus dioses donde no está excluido que ella las encuentre bajo la tierra. Diríamos que la nueva civilización de México podría comenzar allí, al contacto con esas fuerzas negras. (p. 166)

Hacía luego una crítica rotunda del mundo yerto y caduco de la Europa civilizada:

Una civilización que ha perdido sus dioses y que no aprecia más que sus comodidades materiales, es porque las representaciones de sus dioses han perdido todo contacto con lo real. O los dioses vinculados con lo real no son jamás desposeídos de su fuerza 0 es que la vida ha perecido entre ellos. Donde los dioses pasan al estado de efigie es porque su simbolismo era transitorio e ilusorio... (p. 165) 
En las viejas culturas mexicanas hallaba la fuente de nuevas fuerzas del espíritu y la salvación de la humanidad:

Si yo hablo a un francés del fuego, él evocará en su mente $1_{d}$ idea de un fósforo sueco, de la llama del gas, y si se trata de un hombre de gran imaginación, lo asaltaría la idea de un incendio de fábrica, de un navío quemándose en medio del mar. (p. 159)

Pero el fuego, imagen de la civilización, se encuentra en México a través de los tiempos y es más que una imagen; está activamente incorporado a los mitos por los cuales la civilización mexicana manifiesta su vigor. (p. 159)

Si la civilización de México ofrece un ejemplo perfecto de civilizaciones primitivas de espíritu mágico, nos desenvolverá todas las formas de la cultura primitiva y mágica que esta civilización puede comportar: del totemismo al sortilegio, pasando por las jerarquías astrológicas, los ritos del agua, del fuego, del maíz y de las serpientes; de las curaciones por la música y por las plantas, las apariciones en los bosques, etc. Nosotros diremos porqué los mexicanos sienten de tal suerte pavor de las sombras y de la noche en los bosques. (p. 161)

La voluntad de salir de la racionalidad europea impulsaba a Artaud en su empeño de aproximarse al mito latente en las sociedades antiguas de América Latina y a la fascinación de la magia de sus milenarias culturas. Incluso, en sus últimos años, en Rodez, Artaud llegó a dibujarse un apunte en que se representó él mismo como "Rey de los Incas". Seguía operando así la sugestión del mito antiguo de América.

El furor, la angustia y el vértigo $-y$ a veces el desvarío esquizof rénico- condujeron a Antonin Artaud hacia las ignotas realidades mexicanas. A México se había dirigido Artaud para despertar "los dioses que duermen en los museos" y para tomar contacto con

las fuerzas que duermen en toda forma y que no pueden escaparse de una contemplación de las formas por sí mismas, pero que emergen de una identificación mágica con esas fuerzas.

Buscó en ellas - sin hallarlo- el equilibrio perdido o el lenitivo para su alma de creador atormentado. 
Por momentos pudo liberar su espiritu y desembarazarse de torturantes exigencias que una Europa supercivilizada era incapaz de satisfacer.

Otro conspicuo surrealista, que emerge de la literatura europea y típicamente francesa, en busca de nuevas fuentes, Benjamín Péret, ha intentado con notable fortuna y sensibilidad, revelar y divulgar el contenido mítico de las culturas de algunos pueblos americanos. Este acercamiento a las fuentes de la sabiduría popular y este asedio al caudal mítico americano, confirman la inquietud de Artaud y de Michaux. Péret comparte con ellos el criterio de aproximarse poéticamente a esas fuentes sin invadir el campo del estudio etnográfico riguroso.

Pero no se trata ya de la actitud romántica de un Schlegel o de un Herder, que persiguieron descubrir el embrujo de una creación poética de pueblos lejanos en el tiempo o el espacio. La actitud ha cambiado. Ahora se vislumbran los mitos y las creaciones mágicas populares como un contenido presente latinoamericano, como un caudal vivo y virgen, sin contaminaciones, en que el hombre puede integrar su es. píritu, acercándose sin prejuicio en pos de lo humano y no en persecución de lo exótico.

Benjamín Péret coleccionó antológicamente leyendas y relatos populares de la antigua América en libro memorable. ${ }^{15}$ Los agrupó temáticamente, según fuese su materia la vida del cielo, el hombre en $1_{\alpha}$ tierra, lo que aquí lo rodea, las calamidades, el cielo de los héroes, al nacimiento de los dioses, las epopeyas, el milagto de los descubrimientos, el servicio a las divinidades y los tiempos maravillosos y aquello que los determinan.

La selección abarca desde las creaciones de esquimales hasta las de los tehuenches y fueguinos, pasando por aztecas, mayas, quechuas y las tribus amazónicas. Constituye una de las más amplias e integradons selecciones de la expresión popular antigua de toda América.

El interés de Péret por estas expresiones del mito y la leyenda de América nació de una prolongada estada en México por los años 1939 a 1942 y otra estada en Brasil en la década del 50. Péret se ha valido para su selección de textos dispersos en cronistas de Indias, viajeros, misioneros y recopilaciones de estudiosos, etnólogos y folkloristas, pero no ha utilizado un criterio científico ni especializado:

Sólo un criterio poético - dice el mismo Péret en la introducción- ha presidido la elección de los textos que componen la

15 Paule Thévenin, "A. Artaud en la vida", en Amart" Lima, junio de 1970 , No 12, pp. 37-44. 
obra, y este modo de selección no puede ser sino arbitrario desde el punto de vista de toda ciencia.

El compilador se propuso demostrar, pura y llanamente, "los primeros pasos del hombre en el camino del conocimiento", para demostrar también que:

el pensamiento poético aparece ya en la aurora de la humanidad bajo la forma de lenguaje, más tarde bajo el aspecto del mito que prefigura la ciencia, la filosofía y constituye a la vez el primer estado de la poesía y el eje alrededor del cual ella continúa de tornar a una velocidad indefinidamente acelerada. ${ }^{16}$

Esta obra lleva implícito el propósito muy manifiesto de mostrar una poesía no racional, espontánea, automática, nacida de la naturaleza profunda del hombre milenario o secular, acorde con las formulaciones teóricas del surrealismo.

Pero en contraste (y es muy importante anotarlo de paso) muchos de los adláteres latinoamericanos del surrealismo (en los años 30) no acertaron en peregrinar a las fuentes del mito y la magia aborígenes de América, que pudo nutrir con autenticidad su producción. Fue común a ellos la habitual alienación de imágenes y fórmulas estéticas, que estuvo latente en la literatura latinoamericana, entre los siglos xv1 a XIX, mostrando su dependencia de otras corrientes de arte europeo, sin asimilación ni autonomía.

Péret demuestra que Europa se renueva en los últimos años con la captación de vivencias profundas de América Latina, realmente auténticas. A medida que ha pasado el tiempo, quedan ya superados los "pastiches", las "utopías", los convencionales y falsos cuadros de vida de este continente. Hay una inclinación por descubrir las fuentes de la cultura latinoamericana, por acercarse a una América Latina "profunda", y la observación y el interés se centran en los elementos o raíces auténticos y característicos del nuevo mundo. Se han descubierto las cosas de América cuando también sus propios escritores han hecho el encuentro de sus peculiaridades y características propias. A través de un Carpentier, de un Asturias, de un García Márquez, con sus mágicas realidades, la captación de lo americano auténtico y de la arquitectura de su imagen real es más posible y constructiva.

16 B. Péret, Antologie der mytbes, légendes el contes populaives d'Amérique; Paris, Editions Albin Michel, 1960, 414 pp. 
El aparejamiento de la revolución espiritual de Alemania (el Ro. manticismo) con la revolución política de Francia (1789) engen. dró el ideal de un crecimiento inconmensurable de fuerza, libertad y dignidad, decía Dilthey. ${ }^{17}$

Partiendo de esta idea, Juan Larrea, en una explicación socio-histórica, trata de exponer que el surtealismo contemporáneo (sueño y realidad) es

portador inconsciente del mensaje europeo [que] se acerca a este Nuevo Mundo en el actual momento crítico allegándole los medics para comprender realmente los fenómenos poéticos.

América considerada no en su estado presente sino en la plenitud de su destino, potencializa el desarrollo de aquel preludio formidable en su doble designio material y espiritual, sirviendo de síntesis a los dos fenómenos históricos representados por la Revolución occidental -franco-alemana- y su antítesis necesaria la revolución soviética. ${ }^{18}$

México o la América del Sur sirvieron para que los surrealistas afirmaran su concepción integral del mundo y para que asumieran - lejos de la evasión- una actitud social más definida frente al paisaje o el mito deslumbrantes de los latinoamericanos.

ESTUARDo NúNËEZ

Universidad de San Marcos, Lima, Perí

17 W. Dilthey, Hegel y el idealismo, México, Fondo de Cultura Económica, 1949 , p. 219.

18 J. Larrea, Del surrealismo..., cit., p. 96. 